\title{
Differential Recruitment of Auditory Cortices in the Consolidation of Recent Auditory Fearful Memories
}

\author{
๑Marco Cambiaghi, ${ }^{1}$ Anna Grosso, ${ }^{1}$ Annamaria Renna, ${ }^{1}$ and $\odot$ Benedetto Sacchetti ${ }^{1,2}$ \\ ${ }^{1}$ Rita Levi-Montalcini Department of Neuroscience and ${ }^{2}$ National Institute of Neuroscience, University of Turin, I-10125 Turin, Italy
}

\begin{abstract}
Memories of frightening events require a protracted consolidation process. Sensory cortex, such as the auditory cortex, is involved in the formation of fearful memories with a more complex sensory stimulus pattern. It remains controversial, however, whether the auditory cortex is also required for fearful memories related to simple sensory stimuli. In the present study, we found that, $1 \mathrm{~d}$ after training, the temporary inactivation of either the most anterior region of the auditory cortex, including the primary (Te1) cortex, or the most posterior region, which included the secondary (Te2) component, did not affect the retention of recent memories, which is consistent with the current literature. However, at this time point, the inactivation of the entire auditory cortices completely prevented the formation of new memories. Amnesia was site specific and was not due to auditory stimuli perception or processing and strictly related to the interference with memory consolidation processes. Strikingly, at a late time interval $4 \mathrm{~d}$ after training, blocking the posterior part (encompassing the Te2) alone impaired memory retention, whereas the inactivation of the anterior part (encompassing the Te1) left memory unaffected. Together, these data show that the auditory cortex is necessary for the consolidation of auditory fearful memories related to simple tones in rats. Moreover, these results suggest that, at early time intervals, memory information is processed in a distributed network composed of both the anterior and the posterior auditory cortical regions, whereas, at late time intervals, memory processing is concentrated in the most posterior part containing the $\mathrm{Te} 2$ region.
\end{abstract}

Key words: amnesia; fear; long-term memory; memory consolidation; primary auditory cortex; secondary auditory cortex

Significance Statement

Memories of threatening experiences undergo a prolonged process of "consolidation" to be maintained for a long time. The dynamic of fearful memory consolidation is poorly understood. Here, we show that $1 \mathrm{~d}$ after learning, memory is processed in a distributed network composed of both primary Te1 and secondary Te2 auditory cortices, whereas, at late time intervals, memory processing is concentrated in the most posterior $\mathrm{Te} 2$ cortex. Together, our data reveal that the consolidation of fearful memories related to simple auditory stimuli requires the auditory cortex, provided that the inactivation encompasses both the primary and the secondary components of the cortex, and that different regions of the auditory cortex play complementary but different roles in these processes.

\section{Introduction}

Although rapidly acquired, memories of threatening experiences undergo a prolonged process of consolidation to be stabilized and maintained for a long time (McGaugh, 2000, 2015). Memory consolidation involves reorganization at both the synaptic and system levels. Synaptic consolidation is mediated by cellular

Received Feb. 19, 2016; revised June 16, 2016; accepted June 23, 2016.

Author contributions: M.C. and B.S. designed research; M.C., A.G., and A.R. performed research; M.C., A.G., and B.S. analyzed data; M.C. and B.S. wrote the paper.

This work was supported by grants from the European Research Council (ERC) under the European Union's Seventh Framework Program (FP7/2007-20013/ERC Grant 281072).

The authors declare no competing financial interests.

Correspondence should be addressed to Benedetto Sacchetti, National Institute of Neuroscience, University of

Turin, Corso Raffaello 30, Turin 10125, Italy. E-mail: benedetto.sacchetti@unito.it.

DOI:10.1523/JNEUROSCI.0561-16.2016

Copyright $\odot 2016$ the authors $\quad 0270-6474 / 16 / 368586-12 \$ 15.00 / 0$ modifications, which are likely to encode newly acquired memories. Systems consolidation involves interactions between different brain areas and causes a rewiring of the network that encodes enduring memories (Riedel et al., 1999; Frankland and Bontempi, 2005; Lesburguères and Bontempi, 2011).

The amygdala, a subcortical structure made of several nuclei, plays a crucial role in all phases of fearful memory processes (Ledoux, 2000; McGaugh, 2015). Conversely, the role of the sensory neocortex in fear learning and memory processes is still matter of debate. After fear learning, electrophysiological and immunohistochemical studies have provided evidence for learning-induced plasticity in the auditory cortex, which transcends the analysis of physical properties of auditory stimuli and their transmission to the amygdala (for extensive reviews, see Weinberger, 2007, 2015; Brosch et al., 2011; Grosso et al., 2015a). At variance with these findings, however, early attempts to iden- 
tify the neural circuitry underlying learned fear demonstrated that lesions in the auditory cortex of rodents did not prevent the formation of auditory memories of fear (Ledoux et al., 1989; Romanski and Ledoux, 1992a, 1992b). Moreover, these lesions did not affect the retention of auditory fearful memories when they were made shortly after training (Jarrell et al., 1987; Campeau and Davis, 1995). These lesion studies led to the idea that the auditory cortex, although it is involved, is dispensable for emotional memory formation and retrieval.

More recently, two studies have shown that reversible inactivation (Letzkus et al., 2011) and optogenetic manipulation (Weible et al., 2014) of the auditory cortex during training prevented auditory fear learning. Both studies used complex tones, namely frequency-modulated sweeps (Letzkus et al., 2011) and temporally structured sounds (Weible et al., 2014). It has therefore been proposed that the auditory cortex is involved during learning of complex auditory stimulus patterns, whereas it remains controversial whether this cortex is also required for encoding memories formed by pairing simple auditory stimuli with aversive experiences.

Most of these lesion studies were focused on the primary auditory cortex, Tel. Conversely, recent studies have shown that a higher-order component of the auditory stream, specifically the secondary auditory $\mathrm{Te} 2$ cortex, is necessary for long-term storage/retrieval of fearful memories associated with simple auditory stimuli. More specifically, Te2 lesions impaired fearful auditory memories when performed at 1 month after learning, whereas Te2 lesions performed $1 \mathrm{~d}$ after training did not affect recent memory retention (Sacco and Sacchetti, 2010). Furthermore, temporary silencing of the $\mathrm{Te} 2$ at $1 \mathrm{~d}$ after training impaired retention of remote fearful memories, whereas it left memories recent memories intact (Grosso et al., 2015b). Together, these findings suggest that higher-order sensory cortices play a prominent role in the long-term storage/retrieval of remote memories. The role played by these higher-order sensory cortices goes beyond elaboration of stimuli and transmission to the amygdala; they participate in forming and encoding the emotionalmotivational charge linked to perceiving stimuli (Sacco and Sacchetti, 2010; Cambiaghi et al., 2015, 2016; Grosso et al., 2015b).

By showing that fearful memories reorganize with time and that higher-order sensory cortices are essential for the late storage/retrieval of remote memories, these data raise two related issues. Which structures support recent fearful memories? And, are recent versus remote fearful memories encoded by parallel and independent neural circuits? This study aimed to answer these questions.

\section{Materials and Methods}

\section{Subjects}

Male Wistar rats (age, 65-80 d; weight, $250-350 \mathrm{~g}$ ) were used. The animals were housed in plastic cages with food and water available ad libitum with a $12 \mathrm{~h} \mathrm{light/dark} \mathrm{cycle} \mathrm{at} \mathrm{a} \mathrm{constant} \mathrm{temperature} \mathrm{of} 22 \pm 1^{\circ} \mathrm{C}$. All experiments were conducted in accordance with the European Communities Council Directive 2010/63/EU and were approved by the Italian Ministry of Health (authorizations 265/2011 and 322/2015-PR) and by the local bioethical committee of the University of Turin.

\section{Surgery}

The substances were injected at different time intervals (15-20 min, $1 \mathrm{~d}$, $4 \mathrm{~d}$ ) after the completion of the learning trial. The animals were deeply anesthetized with intraperitoneal administration of ketamine (100 $\mathrm{mg} / \mathrm{kg}$; Ketavet; Bayer) supplemented by xylazine ( $5 \mathrm{mg} / \mathrm{kg}$; Rompun; Bayer) and mounted in the stereotaxic apparatus. The injection needle (outside diameter, $0.3 \mathrm{~mm}$ ), connected to a Hamilton syringe, was fixed in the electrode holder of the stereotaxic apparatus and introduced into the target structures. After treatment, the incision was closed with stainless steel wound clips and the animal was given a subcutaneous injection of the analgesic/anti-inflammatory ketoprofen $(2 \mathrm{mg} / \mathrm{kg}$ body weight $)$ and kept warm and under observation until recovery from anesthesia.

Stereotaxic coordinates for the primary Te1 and Te2 were taken from Paxinos and Watson (1986) with cortical fields referenced to Zilles (1985), consistent with our previous studies (Sacco and Sacchetti, 2010; Grosso et al., 2015b). Two pairs of injection sites were planned bilaterally using the following coordinates: for Te1, (1) AP = $4.0, \mathrm{ML}= \pm 6.7, \mathrm{DV}=4.8$ and $(2) \mathrm{AP}=5.3, \mathrm{ML}= \pm 6.8, \mathrm{DV}=4.8$; for $\mathrm{Te} 2,(1) \mathrm{AP}=5.8, \mathrm{ML}= \pm 6.7, \mathrm{DV}=6.0$ and (2) $\mathrm{AP}=6.8$, $\mathrm{ML}= \pm 6.7, \mathrm{DV}=6.0$. Stereotaxic coordinates aimed at inactivating the medial geniculate nucleus (MG) of the thalamus were as follows: $\mathrm{AP}=5.5, \mathrm{ML}= \pm 3.5, \mathrm{DV}=6.0$.

\section{Reversible inactivation procedures}

Reversible inactivation of these structures was made with tetrodotoxin (TTX; $10 \mathrm{ng} / \mu \mathrm{l}$ in physiological saline; Tocris Bioscience). At least $20 \mathrm{~min}$ were necessary to reach maximal neural inactivation, whereas the blockade lasted no less than $120 \mathrm{~min}$, exponentially decreasing and disappearing completely within $24 \mathrm{~h}$ (Zhuravin and Bures, 1991, van Duuren et al., 2007).

To block Te1, a $0.6 \mu$ l volume of TTX or vehicle (physiological saline; $0.9 \% \mathrm{NaCl}$ ) was injected. Mean inactivated nervous tissue radius after TTX administration was estimated at $0.6-0.8 \mathrm{~mm}$ for $5 \mathrm{ng}$ of TTX injection (Zhuravin and Bures, 1991). Although stereotaxic coordinates were centered in the Te1, we cannot rule out that TTX marginally diffused into the adjacent tertiary Te 3 cortex.

To block Te2, a $0.5 \mu$ l volume of TTX or vehicle (physiological saline; $0.9 \% \mathrm{NaCl}$ ) was injected. Although the stereotaxic coordinates were centered in the Te2, we cannot rule out that TTX can affect the posterior part of the Te1 (Paxinos and Watson, 1986).

To inactivate local activity in Te2, but not passing fibers, we administered muscimol $(1 \mathrm{mg} / \mathrm{ml}$ in physiological saline, Tocris Bioscience; Cambiaghi et al., 2015; Grosso et al., 2015b). Given that muscimol effects terminate within a few hours after the injection (Martin and Ghez, 1999), we prolonged its action by injecting it twice on 2 consecutive days (Grosso et al., 2015b).

To inactivate the MG, a $0.5 \mu$ l volume of TTX was administered. Moreover, to achieve a more complete blockade of the MG, we administered a volume of $0.8 \mu \mathrm{l}$ in a second series of experiments. In all cases, the injection rate was $0.25 \mu \mathrm{l} / \mathrm{min}$ and the needle was left in place for 1 min.

Irreversible lesions in Te1 and Te2 were made by injecting $N$-methylD-aspartic acid (NMDA; Tocris Bioscience). NMDA was dissolved in PBS, pH 7.4, to a concentration of $20 \mu \mathrm{g} / \mu \mathrm{l}$ and $0.20 \mu \mathrm{l}$ was injected at the previous stereotaxic coordinates. The needle was left in place after the injection for $3 \mathrm{~min}$. Sham rats underwent an identical procedure except that no infusions were made.

\section{Fear-conditioning paradigm}

Fear-memory acquisition. A Skinner box module was used as a conditioning chamber, as in our previous work (Sacco and Sacchetti, 2010; Grosso et al., 2015b). The box floor was made of stainless steel rods $(1 \mathrm{~cm}$ in diameter, spaced $5 \mathrm{~cm}$ apart) connected to a shock delivery apparatus. The apparatus was enclosed within a sound attenuating chamber. Once inside, the animals were left undisturbed for $2 \mathrm{~min}$. After this time, a series of sensory stimuli acting as conditioned stimuli (CSs) $(8 \mathrm{~s}, 80 \mathrm{~dB}$, $3000 \mathrm{~Hz}, 22 \mathrm{~s}$ intertrial interval) were administered. The final $1 \mathrm{~s}$ of each CS was accompanied with an unconditioned stimulus (US) consisting of a scrambled electric foot shock (intensity, $0.7 \mathrm{~mA}$ ). The rats were left in the chamber for an additional $1 \mathrm{~min}$ and then returned to the home cage. Weaker olfactory fear memories were obtained by using a foot-shock intensity of $0.4 \mathrm{~mA}$.

Fear-memory retention. Recent fearful memories were tested 1 week after the administration of TTX or saline. Conversely, remote fearful memories were tested 1 month after training (Sacco and Sacchetti, 2010). The animals were handled for $3 \mathrm{~d}(5 \mathrm{~min} / \mathrm{d})$ before the memory retention 
trial. Memory was tested using a different apparatus located in a separate experimental room to avoid conditioned fear behavior to contextual cues (Sacchetti et al., 1999, 2002; Sacco and Sacchetti, 2010). The apparatus consisted of a plastic cage with the floor and sides made of transparent plastic and enclosed within a sound-attenuating chamber equipped with an exhaust fan, which eliminated odorized air from the enclosure and provided a background noise of $60 \mathrm{~dB}$. Once inside, the subject was left undisturbed for $2 \mathrm{~min}$. After this time, CSs were administered that were identical to those used during conditioning. Rat behavior was recorded via digital video camera. A freezing response was taken as a fear index (Sacco and Sacchetti, 2010), in which freezing was defined as the complete absence of somatic mobility except for respiratory movements. For each animal, the amount of time (in seconds) spent freezing during the CSs and the total freezing that animals spent during CS presentation and the intertrial time intervals were measured offline. The freezing behavior was analyzed by two independent observers who were blinded to the animal groups (inter-rater and intra-rater reliabilities $\geq 90 \%$ ). Freezing during the $120 \mathrm{~s}$ period preceding the first tone was also recorded to measure any generalization of fear (the pre-CS period).

Fear memory discrimination paradigm. To analyze fear discrimination processes, rats received the presentation of 5 tones $(8 \mathrm{~s}, 80 \mathrm{~dB}, 1000 \mathrm{~Hz}$, $22 \mathrm{~s}$ intertrial interval). Three hours later, the same tones were paired with the US, as in the previous experiments. Memory discrimination was tested 1 week after training by presenting sounds never perceived before $(15 \mathrm{~s}, 80 \mathrm{~dB}, 15000 \mathrm{~Hz}, 22 \mathrm{~s}$ intertrial interval) in a totally new apparatus (see above). One day later, in the same apparatus, the CSs (8 s, $80 \mathrm{~dB}$, $1000 \mathrm{~Hz}, 22 \mathrm{~s}$ intertrial interval) was presented. Freezing was measured during the two trials.

\section{Histology}

At the end of experiments, animals were deeply anesthetized and intracardially perfused with $4 \%$ formaldehyde. Brains were cut with a freezing microtome and injection needle tracks were identified in Nissl-stained serial sections. Rats with histological evidence that was not adequate were excluded from the data processing.

\section{Statistical analysis}

Student's $t$ tests, one-way (with the time spent freezing as a dependent variable) ANOVA tests, and Newman-Keuls multiple-comparisons test were used for comparing the different behavioral groups. Significant differences were reported at a $p=0.05$ level. The degrees of freedom were $n-1$ throughout. The statistical analyses were performed using SPSS version 22.0 software.

\section{Results \\ Auditory cortex is necessary for early consolidation of recent fear memories}

First, we addressed the question of whether the auditory cortex is involved in the formation of recent fear memories. In particular, it is possible that, upon encoding, memory is widely processed in the main auditory stream, so blocking only one auditory structure does not cause memory impairment. To address this, we performed the combined blockade of both the anterior and posterior regions of the auditory cortex during memory consolidation process. As also detailed in the Materials and Methods section, the anterior region contains the core area of the auditory cortex, the so-called Te1, whereas the posterior region contains part of the belt area encompassing the Te2 (Zilles, 1985). However, the precise borders of Te1 and Te 2 may vary between individual animals. Furthermore, at the most anterior Te2 injection site, there is also the most posterior region of Tel (Zilles, 1985; Paxinos and Watson, 1986). Therefore, it could be very difficult to define precisely where the Tel cortex ends and the Te 2 cortex starts without electrophysiological recordings to validate cortical borders based on functional distinctions. Therefore, in the present study, we use the term Tel to refer to the most anterior region, which encompasses the core area, the term $\mathrm{Te} 2$ to refer to the most posterior region, which mainly includes the posterior part of the belt area; these are consistent with the previous literature (Romanski and Ledoux, 1993; Campeau and Davis, 1995; Sacco and Sacchetti, 2010; Grosso et al., 2015b; Grosso et al., 2016).

Rats were trained to associate a simple acoustic stimulus (CS) with aversive ones (US). To block long-term memory consolidation, which is thought to require fast synaptic transmission for several hours and days (Riedel et al., 1999; Frankland and Bontempi, 2005; Lesburguères et al., 2011), we administered TTX, a long-acting sodium-channel blocker (Sacchetti et al., 2002; Lesburguères and Bontempi, 2011; Grosso et al., 2015b) in the target structures at $1 \mathrm{~d}$ after learning (Fig. 1A; Lesburguères et al., 2011; Grosso et al., 2015b). After 1 week, we tested recent fear memory retention by measuring the freezing response to the CS in the absence of the US (Fig. 1B). Using this procedure, it was possible to interfere selectively with memory processes occurring during the consolidation period without interfering with the acquisition or the retrieval phases (Riedel et al., 1999; Sacchetti et al., 1999, 2002).

Compared with the control group $(n=8)$, rats that received TTX into the anterior $(\mathrm{Te} 1)+$ the posterior $(\mathrm{Te} 2)$ auditory cortices $(n=8)$ showed a statistically significant decrease in freezing responses during CS presentation (Student's $t$ test, $t_{(14)}=16.50, p<$ 0.001 ; Fig. $1 C$ ). We observed similar effects by analyzing the total time that animals spent freezing during CS presentation and the intertrial time intervals $\left(t_{(14)}=15.71, p<0.001\right.$; Fig. 1D). Because the retention trial was performed well after the TTX effects were over, amnesia cannot be ascribed to auditory cortex functional impairment at the moment of the test. Nissl-stained inspection confirmed the absence of any permanent cortical damage (Fig. $1 \mathrm{~A}$ ) and amnesic rats were able to relearn new aversive memories, as shown by the lack of differences between TTX-treated and control rats after reacquisition of memories $\left(t_{(14)}=-1.951, p>0.05\right.$; Fig. 1C,D). Therefore, the auditory cortex encompassing both the Tel and the $\mathrm{Te} 2$ area is necessary for early consolidation of fearful memories related to simple auditory CSs.

Our previous studies showed that Te2 blockade alone did not affect recent fearful memories (Sacco and Sacchetti, 2010; Grosso et al., 2015b). The present data therefore raises the question of whether Te1 alone is necessary for the consolidation of recent fearful memories. To address this question, we repeated the previous experiment by inactivating most of the Tel alone (Fig. 1E). In this condition, no differences were detected between salinetreated $(n=7)$ and TTX-treated $(n=7)$ rats in freezing during CS presentation $\left(t_{12}=0.26, p>0.05\right.$; Fig. $\left.1 F\right)$ or during CSs and intertrial time intervals $\left(t_{12}=-0.04, p>0.05\right.$; Fig. $\left.1 G\right)$, thus revealing that blocking Tel alone is not sufficient to hamper fearful memories.

A recent study demonstrated that sudden inactivation techniques and optogenetic manipulations may affect neural activity in downstream circuits, so amnesic effects may be related to these secondary effects (Otchy et al., 2015). Such off-target effects can be resolved after the targeted area is permanently lesioned (Otchy et al., 2015). Therefore, to determine whether, in the present study, amnesia was due to interference selectively with local processes occurring in the auditory cortex, we lesioned the Te1+ Te 2 cortex $1 \mathrm{~d}$ after training by administering NMDA (Sacco and Sacchetti, 2010; Grosso et al., 2015b; Fig. 1H). NMDA did indeed induce neuronal cell loss, but spared the fibers of passage, so amnesia, when present, is not secondary to interference with the passing axons. Compared with the sham-treated rats $(n=6)$, lesioned rats $(n=6)$ displayed amnesic effects either during CS 
A
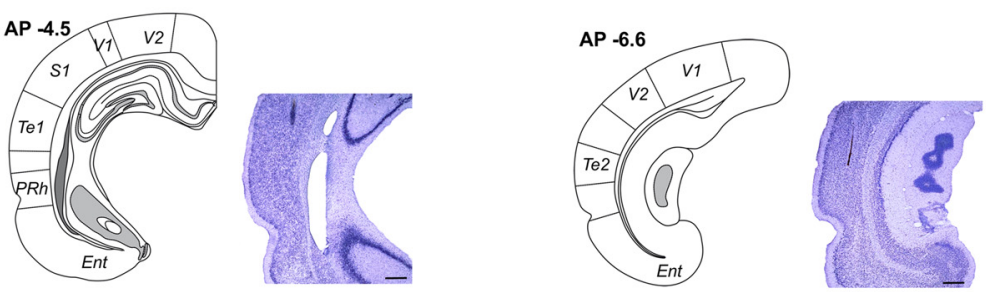

B CS-US $\underset{\substack{\text { Saline/TTX } \\ \text { Te1+Te2 }}}{\stackrel{\text { one day }}{\longrightarrow} \text { one week }}$ CS

C

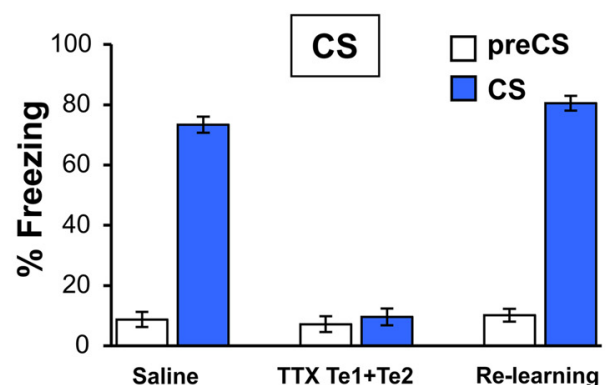

D

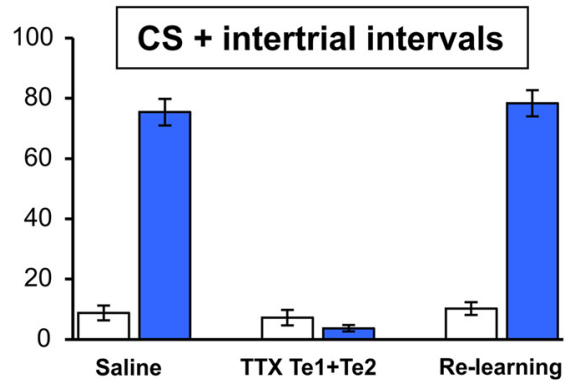

E

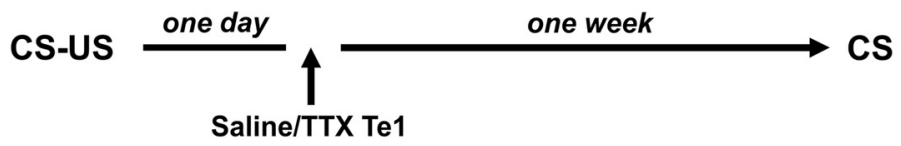

$\mathbf{F}$

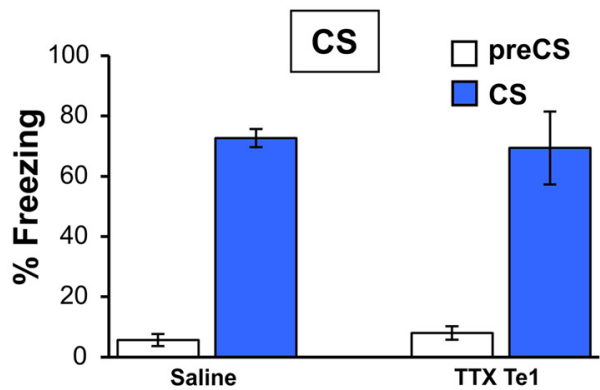

G

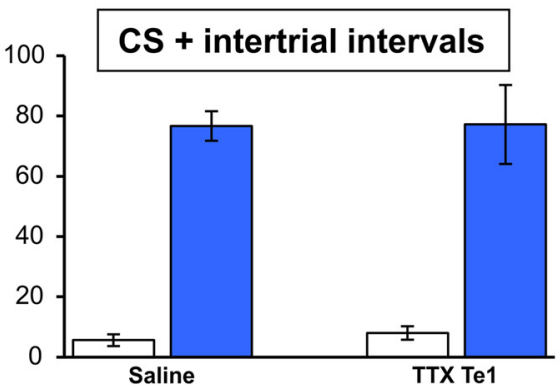

H

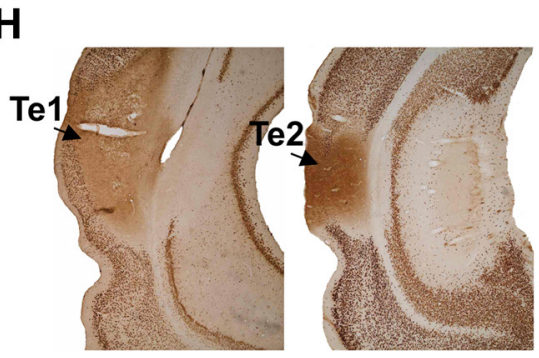

I

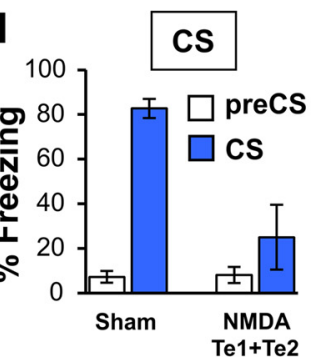

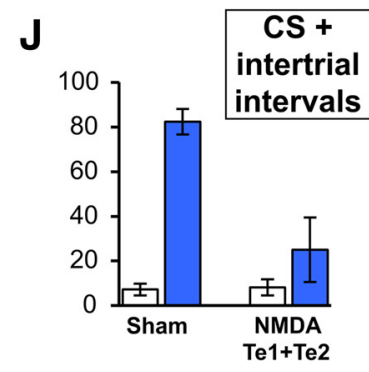

Figure 1. Recruitment of the auditory cortex, including the Te1 and Te2 cortex, in consolidating recent fearful memories to simple auditory stimuli. $A$, Localization of TTX injection in the Te1 (left) and Te2 (right) area. Plates are adapted from the atlas of Paxinos and Watson (1986). Te2 was defined according to the atlas of Zilles (1985). Plates were taken at the AP coordinates of 4.5 for Te1 and 6.6 for Te2 in millimeters from the bregma. The localization of injections was confirmed by Nissl staining. Representative histology of the needle track in the Te1 and Te2. Scale bar, $500 \mu \mathrm{m}$. Ent, Enorhinal cortex; PRh, peririnal cortex; S1, primary sensory cortex; V1, primary visual cortex; V2 secondary visual cortex. B, Experimental design of Te1 and Te2 blockade performed $1 \mathrm{~d}$ after CS-US pairing. C, Fear response measured as a percentage of total immobility (freezing) both at 2 min before (pre-CS) and during the overall CS presentation (CS) in saline- and TTX-injected rats and in TTX-treated rats after relearning. $\boldsymbol{D}$, Similar results were observed by measuring overall freezing responses during CS presentation and intertrial time intervals. $\boldsymbol{E}$, Experimental design of Te 1 alone blockade performed $1 \mathrm{~d}$ after CS-US pairing. $\boldsymbol{F}$, $\boldsymbol{G}$, Te1 alone inactivation did not affect recent fear memories to the overall CS presentation $(\boldsymbol{F})$ or to the total time spent freezing during $C S$ presentation and intertrial intervals $(\boldsymbol{G})$. $\boldsymbol{H}$, Representative histology of the Te1 + Te2 excitotoxic lesions obtained though NMDA injection. Scale bars, $500 \mu \mathrm{m}$. I, J, Fear responses in Te1 + Te2 lesioned rats and in sham-operated animals toward CSs (I) and to the total time spent freezing during $C S$ presentation and intertrial intervals. All values are reported as mean \pm SEM. 
A
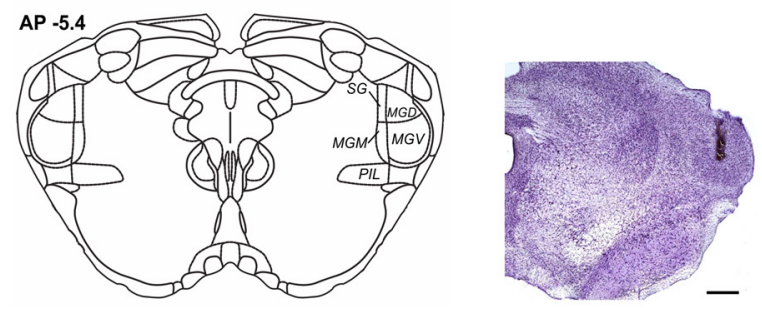

B

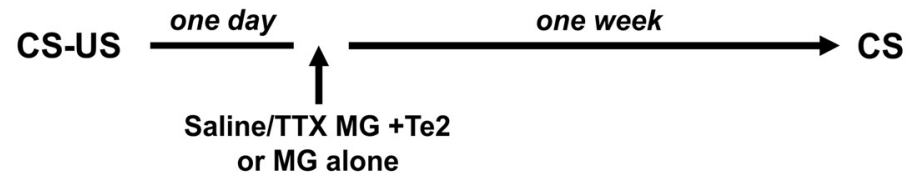

C

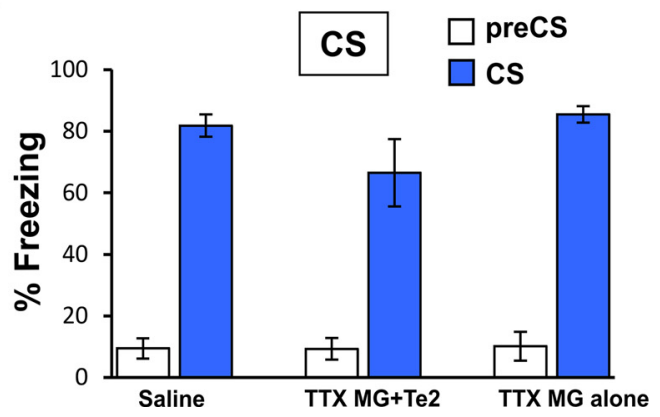

D

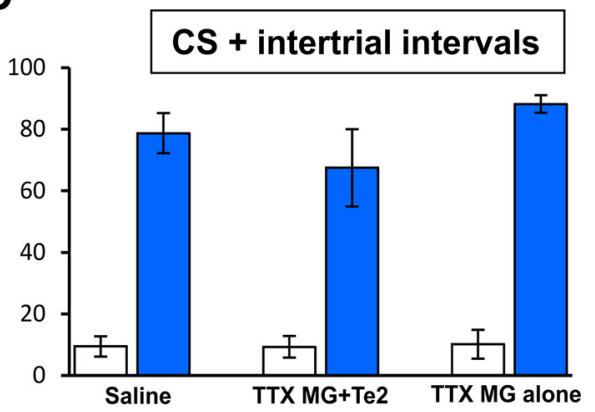

Figure 2. The combined blockade of auditory thalamic nuclei and the Te2 cortex left recent fear memories unaffected. $A$, Schematic localization (left) and needle track (right) in the MG, including the dorsal (MGD), medial (MGM), and ventral (MGM) divisions. PIL, Postintralaminar thalamic nucleus; SG, suprageniculate thalamic nucleus. Scale bar, $500 \mu \mathrm{m}$. Plates are adapted from the atlas of Paxinos and Watson (1986). B, Experimental design of MG and Te2 blockade performed $1 \mathrm{~d}$ after (S-US pairing. C, D, Fear response measured as a percentage of total immobility (freezing) both at 2 min before (pre-CS) and during the overall CS presentation (CS) in saline- and TTX-injected rats. MG + Te2 combined blockade or the MG alone blockade did not affect recent fear memories to the overall $C S$ presentation $(\boldsymbol{C})$ and to the total time spent freezing during $(S$ presentation and intertrial intervals $(\boldsymbol{D})$. All values are reported as mean \pm SEM.

administration $\left(t_{(10)}=3.94, p<0.005\right.$; Fig. $\left.1 I\right)$ or during overall freezing $\left(t_{(10)}=3.67, p<0.005\right.$; Fig. $\left.1 J\right)$.

\section{Auditory cortices, but not auditory thalamic nuclei, are} necessary for consolidating recent fearful memories

Our findings raise the question of whether auditory fearful memories are specifically distributed across auditory cortices or if other subcortical sites in the auditory stream, such as the auditory thalamic nuclei, are responsible for the lack of effects observed afater $\mathrm{Te} 2$ alone blockade. In other words, $1 \mathrm{~d}$ after learning, thalamic nuclei may encode fear memories so they may support the functional absence of Te2 cortex. To address this issue, we investigated whether the combined blockade of Te2 and the MG affected recent fear memory retention. Stereotaxic coordinates, TTX dosage and volume were selected to inactivate the dorsal, ventral, and medial division of the MG (Fig. $2 A$ ). In addition, to better define the involvement of MG in fear memory consolidation processes, we included an additional group in which we inactivated the MG alone with a larger volume of TTX ( 0.8 vs 0.5 $\mu \mathrm{l})$. One day after training, we administered TTX to inactivate both Te2 and MG $(n=8)$ or the MG alone $(n=8)$ and, 1 week later, we tested memory retention (Fig. $2 B$ ). Compared with control animals $(n=6)$, no differences were detected in rats that received TTX into MG $+\mathrm{Te} 2$ and those that received TTX into the MG alone either in freezing responses to CSs $\left(F_{(2,19)}=2.00\right.$, $p>0.05$; Fig. $2 C)$ and overall freezing responses $\left(F_{(2,19)}=1.53\right.$, $p>0.05$; Fig. $2 D$ ). Together, our data revealed that auditory fearful memories are specifically consolidated at the auditory cortex level, whereas thalamic nuclei are not necessary for this pro- cess. Therefore, MG may be involved in the acquisition and retrieval processes, as reported previously (Campeau and Davis, 1995; Antunes and Moita, 2010; Weinberger, 2011), whereas it is dispensable for the consolidation of long-term memories.

Temporal recruitment of the auditory cortex in the early and late consolidation of recent fearful memories

We then investigated the temporal dynamics of the auditory cortex involvement in the memory consolidation process. We injected TTX at a later time point after fear learning, at $4 \mathrm{~d}$ after training (Fig. $3 A$ ). Strikingly, at this time interval, TTX administration in Te2 alone $(n=8)$ produced a marked decrease in freezing responses to the $\mathrm{CS}\left(t_{(13)}=7.10, p<0.001\right.$; Fig. $\left.3 B\right)$, as well as to the overall freezing $\left(t_{(13)}=6.65, p<0.001\right.$; Fig. $\left.3 C\right)$, compared with control animals $(n=7)$. In addition to local activity, TTX also blocks the fibers of passage (Martin and Ghez, 1999). Therefore, we repeated the experiments using muscimol, a $\mathrm{GABA}_{\mathrm{A}}$ receptor agonist that reversibly blocks only local neurons (Martin and Ghez, 1999). As in our previous study (Grosso et al., 2015b), given that the effects of muscimol terminate within a few hours after injection (Martin and Ghez, 1999), we prolonged its action by injecting it on 2 consecutive days. One-way ANOVA and Newman-Keuls multiple-comparisons test showed that muscimol administration in Te2 alone $(n=7)$ produced a marked decrease in freezing responses to the $\operatorname{CS}\left(F_{(2,19)}=36.99\right.$, $p<0.001$; Fig. $3 B)$, as well as to the overall freezing $\left(F_{(2,19)}=\right.$ $45.55, p<0.001$; Fig. $3 C$ ), compared with the control animals, whereas it elicited similar effects to those detected after TTX administration ( $p>0.05$; Fig. $3 B, C)$. 


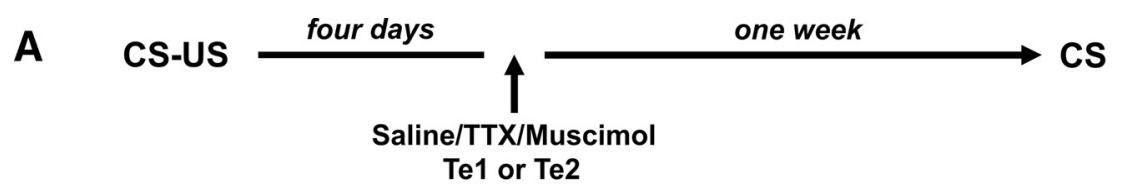

B

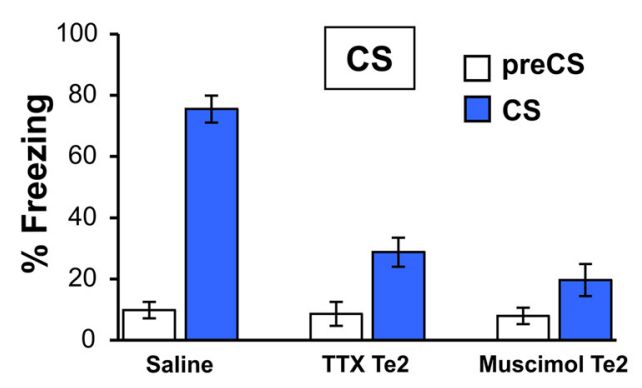

D

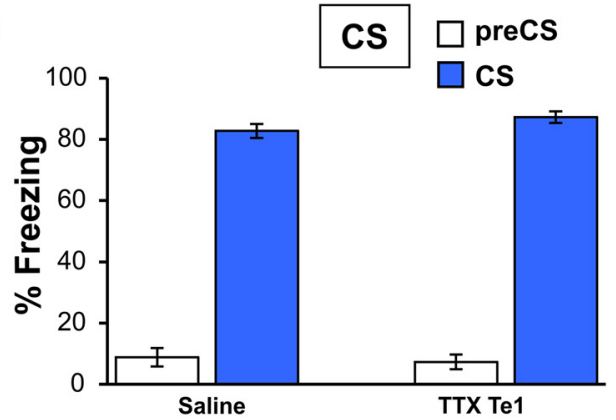

C

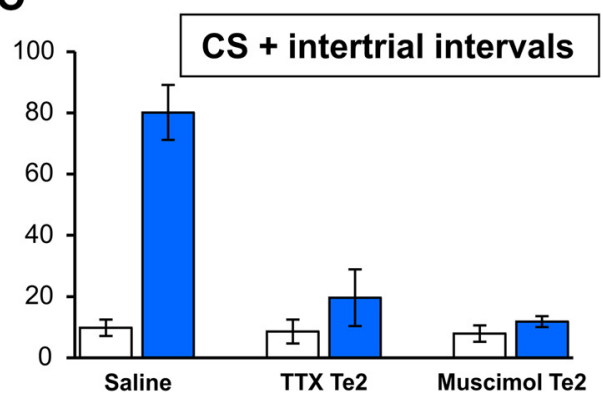

E

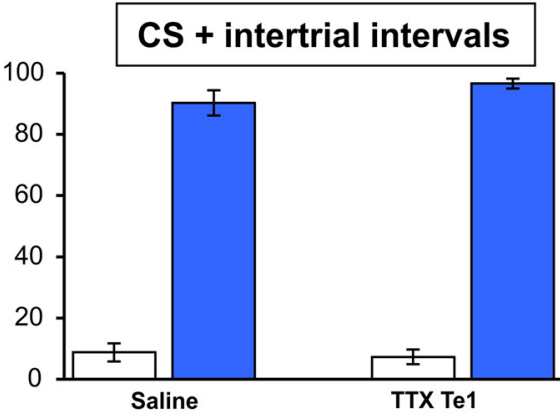

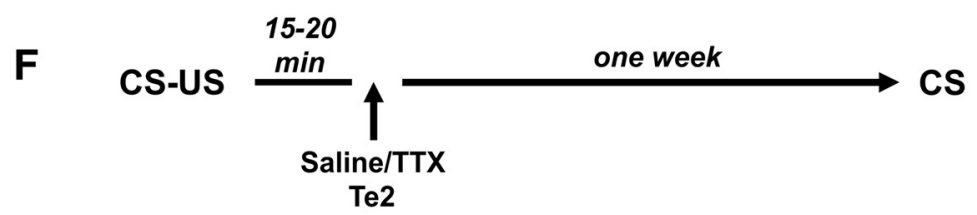
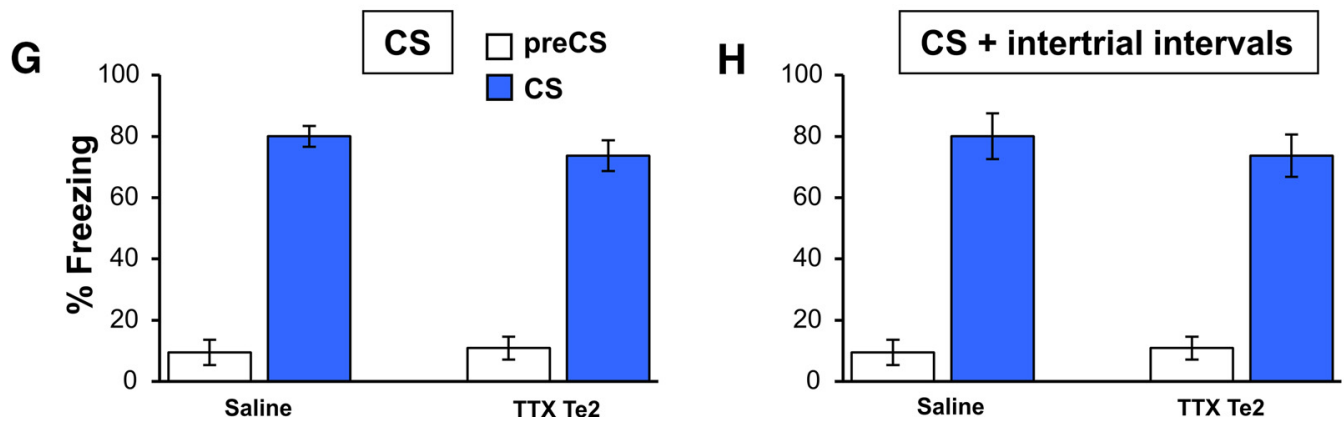

Figure 3. Differential recruitment of Te2 versus Te1 cortex at the late time interval of the consolidation of recent fearful memories. A, Schematic design of Te1 or Te2 inactivation performed at $4 \mathrm{~d}$ after training. $\boldsymbol{B}, \boldsymbol{C}$, Blockade of Te2 alone obtained by administering TTX or muscimol into the Te2 impaired the subsequent fear memory recall, measured as freezing to the overall CS presentation $(\boldsymbol{B})$ and to the total time spent freezing during $C S$ presentation and intertrial intervals $(\boldsymbol{C}, \boldsymbol{D}, \boldsymbol{E}$, Conversely, at the same time point, Te1 inactivation did not affect fear memories. $\boldsymbol{F}$, Experimental design of Te2 blockade performed 15-20 min after CS-US pairing. G, Te2 inactivation performed shortly after training did not affect recent fear memories. Fear response measured as a percentage of total immobility (freezing) both at 2 min before (pre-CS) and during the overall CS presentation (CS) in saline- and TTX-injected rats. $\boldsymbol{H}$, Similar results were observed by measuring overall freezing responses during $C S$ presentation and intertrial time intervals. All values are reported as mean $\pm \mathrm{SEM}$.

We then investigated whether blocking Tel alone at this late time interval affects fearful memories. To address this, we repeated a similar experiment by administering TTX into Te1 $(n=7$; Fig. $3 A)$. At variance with the $\mathrm{Te} 2$ results, $\mathrm{Te} 1$ inactivation alone did not impair memory retention $\left(\mathrm{CSs} ; t_{(11)}=-1.53, p>0.05\right.$; overall freezing CSs + intertrial intervals; $t_{(11)}=-1.52, p>0.05$; Fig. $\left.3 D, E\right)$.

Together, these data indicate that, at the sensory neocortex level, memory reorganizes with time and that, at late time points,
$\mathrm{Te} 2$ is more prominently required than Te1 in consolidation processes. More specifically, these data suggest that memory information upon encoding is broadly distributed across the Te1 and Te 2 cortices and, as the memory consolidation occurs, memories become more restricted to the higher-order components of the auditory stream. Indeed, the data also indicate that the Te 2 cortex is also essential for late consolidation of recent fearful memories, and is not only devoted to the encoding of remote memories, as 


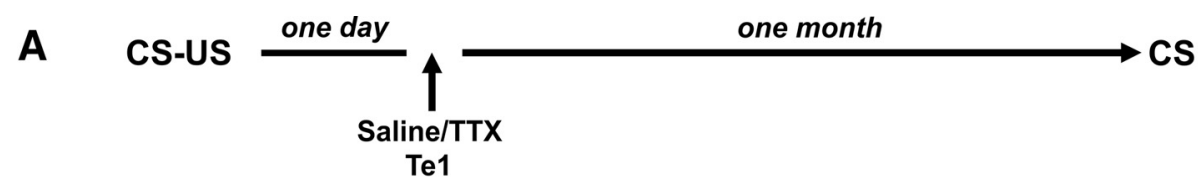

B

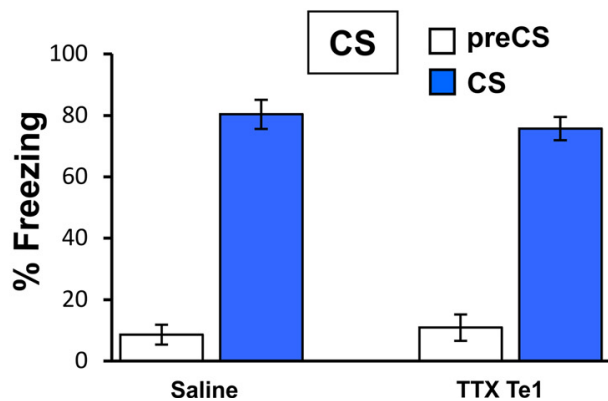

C

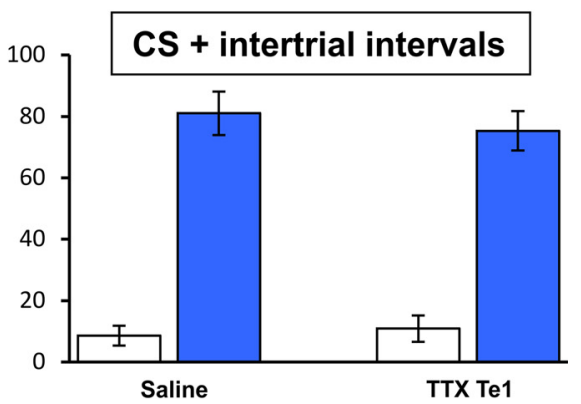

Figure 4. Te1 inactivation did not affect remote fear memories. $\boldsymbol{A}$, Experimental design showing Te1 temporary inactivation performed $1 \mathrm{~d}$ after CS-US pairing and memory retention tested 1 month later. $\boldsymbol{B}$, Te1 inactivation did not affect remote fear memories. Fear response measured as a percentage of total immobility (freezing) both at 2 min before (pre-CS) and during the overall CS presentation (CS) in saline- and TTX-injected rats. C, Similar results were observed by measuring overall freezing responses during CS presentation and intertrial time intervals. All values are reported as mean \pm SEM.

was suggested previously (Sacco and Sacchetti, 2010; Grosso et al., 2015b).

Finally, to provide a complete picture of $\mathrm{Te} 2$ participation in early and late consolidation processes, we tested whether Te2 blockade alone would affect memories if performed immediately after training. Therefore, we blocked Te2 at 15-20 min after completing the learning trial (Fig. $3 F$ ). At this time interval, no differences were detected between control $(n=6)$ and TTX-treated $(n=7)$ rats $\left(\mathrm{CSs} ; t_{(11)}=0.99, p>0.05\right.$; overall freezing CSs + intertrial intervals; $t_{(11)}=0.62, p>0.05$; Fig. $\left.3 G, H\right)$, suggesting that, at this earlier time interval, Te2 alone is not necessary for memory formation.

\section{Different involvement of the Te1 cortex and the Te 2 cortex in early formation of remote fearful memories}

So far, our experiments addressed the involvement of Tel and $\mathrm{Te} 2$ in the formation of recent fearful memories. However, in a previous study, we showed that $\mathrm{Te} 2$ inactivation alone at $1 \mathrm{~d}$ after learning impaired remote memories tested 1 month after training (Grosso et al., 2015b). Therefore, in the present study, we also investigated whether Te1 alone is essential for consolidating remote memories. Rats were trained as in the previous experiments and TTX was administered to the Te1 cortex $1 \mathrm{~d}$ after training. Remote memory retention was tested 1 month later (Fig. 4A). No differences were detected between control $(n=6)$ and TTXtreated $(n=7)$ rats in the freezing responses to the CSs $\left(t_{(11)}=\right.$ $0.76, p>0.05$; Fig. $4 B$ ) or during CSs and intertrial time intervals $\left(t_{(11)}=0.60, p>0.05\right.$; Fig. $\left.4 C\right)$. These data highlighted another important difference between the Te1 and the Te 2 cortex. Overall, they suggest that Te 2 is essential for the late consolidation of recent memories and for forming remote memories, whereas Te1 is only necessary for recent memory consolidation in association with $\mathrm{Te} 2$ at the early stage of consolidation processes and, by itself, is not necessary for the consolidation of remote memories obtained by pairing a simple auditory CS to the US.

\section{Discriminative fear memory processes in the absence of the auditory cortices}

By demonstrating a marked difference between the Te1 and Te2 cortices in the formation of fearful memories, our data raise the question of the role(s) played by these cortices in memory pro- cesses. According to previous studies (Poremba et al., 1997, 1998; Bao et al., 2001; Sacco and Sacchetti, 2010; Cambiaghi et al., 2015; Grosso et al., 2015b), Te2 is essential for the encoding of the association between a tone and its emotional/motivational learned charge, not merely for the processing or encoding of the physical attribute of the CS. The fact that only the combined, not the individual, blockade of Te 2 and Tel impaired recent memory consolidation suggests that Tel participates in memory information. However, how precise is this information? In other words, we addressed the question of whether, in the absence of Te2, Te1 was able to support discriminative memory retention or if the lack of amnesia was due to enhanced fear generalization processes. To answer this question, we analyzed fear memory discrimination, the ability to discriminate between the CS and new neutral tones, in animals in which Te 2 was inactivated $1 \mathrm{~d}$ after training.

Two complementary approaches were used. In a first series of experiments, we presented the auditory stimuli (CS) several hours before its pairing with the US. This procedure has been reported to determine a high level of discrimination (Vervliet et al., 2010). In a parallel series of experiments, rather than manipulating the CS, we modulated the intensity of the foot shock (US), another procedure that is known to modulate fear memory discrimination processes (Laxmi et al., 2003; Ghosh and Chattarji, 2015). These experiments were performed to reveal whether rats are able to discriminate between fearful and neutral auditory cues in the absence of $\mathrm{Te} 2$ memory-related processes.

In the first series of experiments, $3 \mathrm{~h}$ before the start of fear learning, rats were presented with auditory stimuli alone (Fig. $5 A$ ). Subsequently, they received the pairing of these tones with foot shock. One week later, fear discrimination was tested by first presenting a never-previously presented tone and, $1 \mathrm{~d}$ later, by presenting the CS previously paired to foot shock (Fig. 5A). Control rats $(n=9)$ displayed a good level of discrimination, as shown by the low level of freezing responses toward the new tone and the higher level of freezing toward the CS (Fig. 5B,C). Remarkably, fear discrimination was also high in animals that received TTX immediately after $(n=8)$ or $1 \mathrm{~d}$ after $(n=9)$ training (Fig. $5 B, C$ ). No differences were detected between the groups in the freezing responses to the new tone (freezing during new tones; one-way ANOVA $F_{(2,23)}=0.23, p>0.05$; overall freezing; 

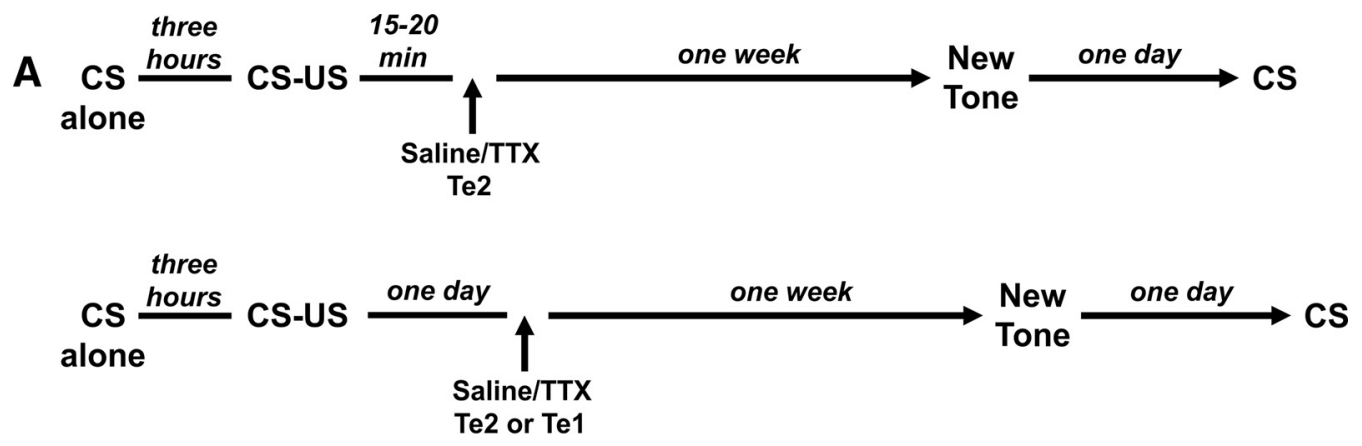

B
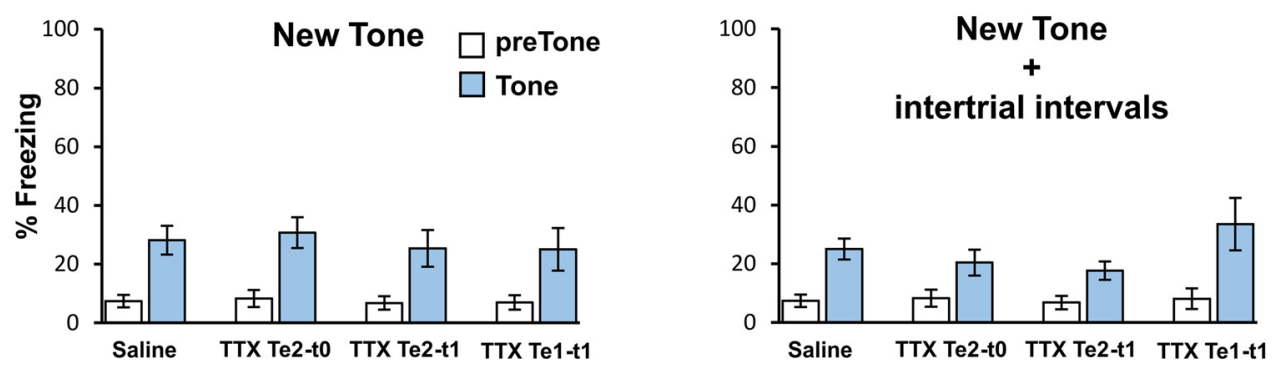

C
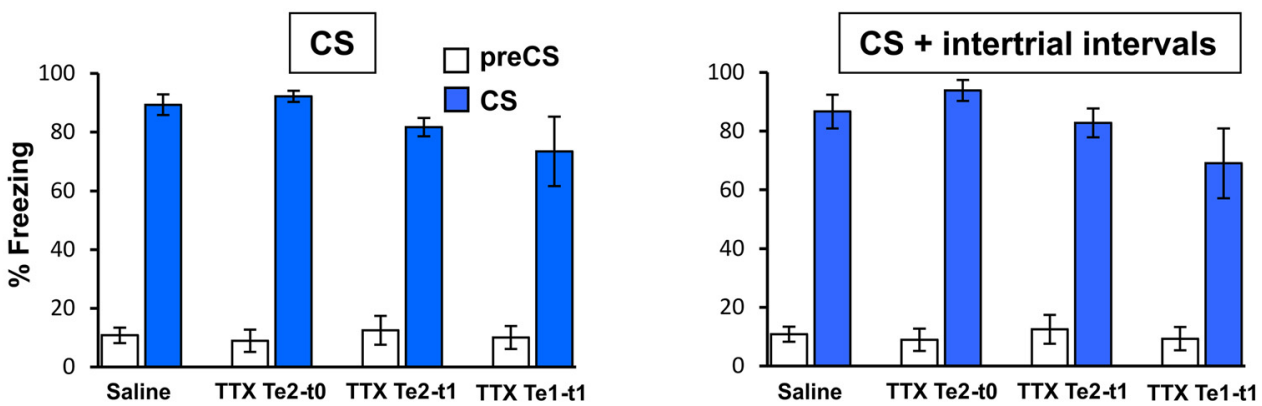

D

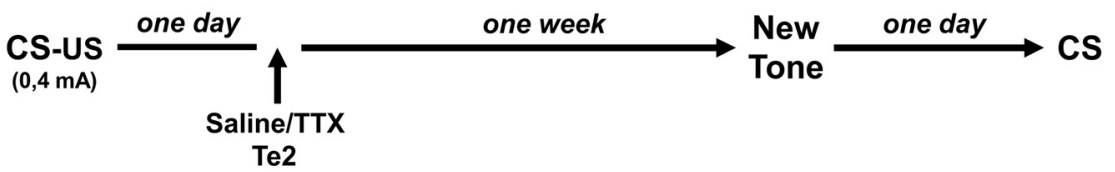

E
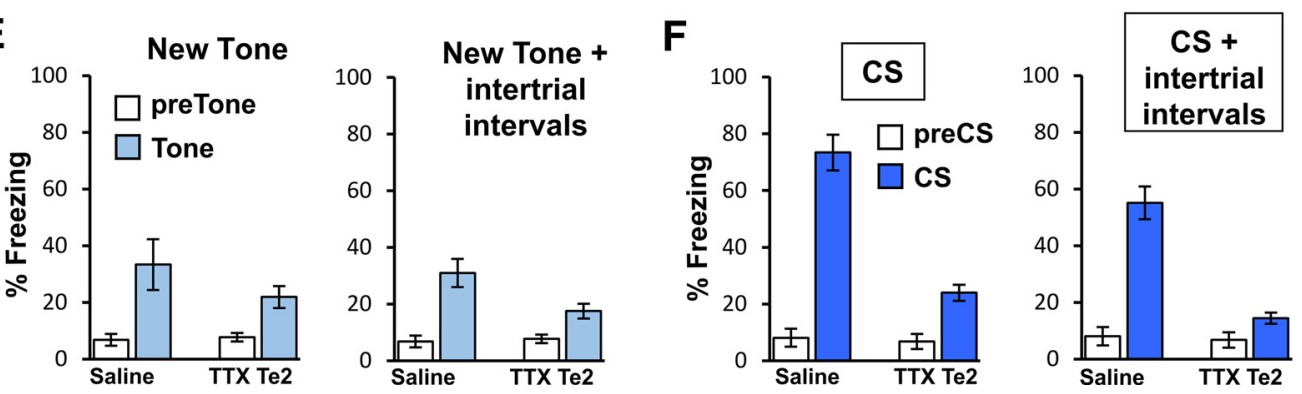

Figure 5. Fear memory discrimination was unaffected after Te2 inactivation. $\boldsymbol{A}$, Experimental design showing Te2 temporary inactivation performed 15-20 min (Te2-t0) after CS-US pairing and fear memory discrimination tested by presenting a never-previously perceived tone and, $1 \mathrm{~d}$ later, the CS previously paired to the foot shock. The CS was presented alone $3 \mathrm{~h}$ before CS-US pairing. In a similar experimental procedure, TTX was administered $1 \mathrm{~d}$ after training in Te2 (Te2-t1) or in the Te1 (Te1-t1). $\boldsymbol{B}$, Histograms showing freezing to the neutral tones (left) and during neutral tones and intertrial intervals (right) in saline- and TTX-treated rats at t0 or t 1 time intervals. C, Freezing measured to the CSs (left) and during CSs and intertrial intervals (right) in saline- and TTX-treated rats. $\boldsymbol{D}$, Fear discrimination was also tested by decreasing the intensity of the US. $\boldsymbol{E}$, Histograms showing freezing to the neutral tones (left) and during neutral tones and intertrial intervals (right) in saline- and TTX-treated rats. $\boldsymbol{F}$, Freezing responses to the CSs (left) and during CSs and intertrial intervals (right) were lower in TTX-treated rats compared with control animals. All values are reported as mean \pm SEM.

$\left.F_{(2,23)}=1.06, p>0.05\right)$, or to the CSs $\left(\mathrm{CSs} ; F_{(2,23)}=3.23, p>\right.$ 0.05 ; overall freezing; $\left.F_{(2,23)}=1.36, p>0.05\right)$. These results showed that, in the absence of Te2, Te1 alone was able to support memory discrimination processes. To address this issue further, we tested whether rats could discriminate between auditory cues when $\mathrm{Te} 1$ was blocked $1 \mathrm{~d}$ after learning. We found that fear discrimination was high in animals that received TTX in Te1 $(n=7)$ $1 \mathrm{~d}$ after training (Fig. $5 \mathrm{~B}, \mathrm{C}$ ). No differences were detected among groups in freezing responses to the new tone (freezing during new tones; one-way ANOVA $F_{(2,29)}=0.19, p>0.05$; overall freezing; $\left.F_{(2,29)}=1.76, p>0.05\right)$ or to the CSs (CSs; $F_{(2,29)}=2.00, p>0.05$; overall freezing; $\left.F_{(2,29)}=2.20, p>0.05\right)$. 
In a parallel line of experiments, we decreased the intensity of the US (Fig. 5D; Laxmi et al., 2003; Ghosh and Chattarji, 2015). When presented with the new neutral tone, both control $(n=8)$ and TTX-injected $(n=8)$ rats showed a low level of freezing (freezing during new tones; $t_{(14)}=1.17, p=0.09$; overall freezing; $t\left(_{16)}=2.39, p=0.031\right.$; Fig. $\left.5 E\right)$. Strikingly, when presented with the CS, TTX-treated rats showed a low level of freezing responses $\left(\mathrm{CSs} ; t_{(14)}=6.24, p<0.001\right.$; overall freezing; $t_{(14)}=$ $6.71, p<0.001$; Fig. $5 F$ ). The latter result showed that Te2 alone is necessary for the consolidation of memories characterized by a weaker emotional strength. Moreover, it suggested that Te1compensating processes are only engaged by auditory fearful memories of increased emotional strength, whereas weaker memories are totally dependent on $\mathrm{Te} 2$ processes, thus supporting the view that Te2 is deeply involved in the early and late consolidation of recent fearful memories to simple auditory CSs.

\section{Discussion}

In this study, we found that, $1 \mathrm{~d}$ after learning, the combined, but not the individual, temporary inactivation of Te 1 and $\mathrm{Te} 2$ totally hampered the retention of recent memories. At a later time interval, $4 \mathrm{~d}$ after training, Te2 but not Te1 inactivation alone impaired recent memory retention. Finally, Te1 inactivation alone did not impair the retention of remote memories, unlike our previous data showing that $\mathrm{Te} 2$ inactivation at the same time interval impaired these memory traces.

These data are schematized in Figure 6, in which the present and previous data that we obtained about auditory cortex participation in the consolidation of fear memories are presented together. The obtained results revealed that the memorization of fearful memories related to simple auditory stimuli requires the auditory cortex, provided that the inactivation encompasses both the primary and the secondary components of the cortex, and that $\mathrm{Te} 1$ and $\mathrm{Te} 2$ play complementary but different roles in fearful memory processes.

Finally, our findings also showed that recent versus remote memories are differentially affected by auditory cortex inactivation, thus suggesting that they are encoded by complementary but different processes.

\section{Primary and higher-order auditory cortices: definition and caveats}

In the present study, we referred to $\mathrm{Te} 1$ and $\mathrm{Te} 2$ on the basis of stereotaxic coordinates (Paxinos and Watson, 1986), with cortical divisions referred to as in the Zilles atlas (Zilles, 1985). Rodents' auditory cortex is divided into a central core and a surrounding belt region. The central area, corresponding to area Te1 of Zilles, is assumed to be the primary auditory cortex, whereas the surrounding regions, (area Te2 and Te 3 of Zilles) are considered higher-order cortices (Kolb and Tees, 1990; Paxinos, 2004). Therefore, on the basis of the previous literature (Romanski and Ledoux, 1993; Campeau and Davis, 1995; Sacco and Sacchetti, 2010; Grosso et al., 2015b; Grosso et al., 2016), in the present study, we refer to the Te1 and Te 2 cortex. Nevertheless, the precise boundaries that separate Te1 and Te 2 are difficult to define without electrophysiological validation. Indeed, they often vary between individuals. Therefore, this terminology should be taken carefully. Nevertheless, our findings clearly revealed that, in the auditory cortical stream, there are functional differences across the anterior-posterior pole that do not necessarily correspond to a distinction between Te1 and Te 2 cortex.

\section{Auditory cortex is essential for consolidating fearful memories associated with simple auditory CSs}

To date, several studies have reported learning-evoked changes in the auditory cortex, either in the Te1 cortex or the Te2 cortex, after emotional learning (Weinberger, 2007, 2015; Brosch et al., 2011; Grosso et al., 2015a for extensive reviews). Auditory neurons in the Tel shift their frequency tuning so as to emphasize tones that signal reinforcement (Bieszczad and Weinberger, 2012; David et al., 2012; Pi et al., 2013; Yin et al., 2014) to predict future behavioral responses (Jaramillo and Zador, 2011; Letzkus et al., 2011; Znamenskiy and Zador, 2013). Similar results have been reported in the higher-order auditory cortex (Poremba et al., 1997, 1998; Villa et al., 1999; Bao et al., 2001; Atiani et al., 2014; Cambiaghi et al., 2016).

Conversely, lesioning studies performed before (Ledoux et al., 1989; Romanski and Ledoux, 1992a, 1992b) or shortly after (Jarrell et al., 1987; Campeau and Davis, 1995) fear learning failed to reveal any amnesic effects. Remarkably, in one of the two studies not finding evidence that cortical blockade affected memory processes when performed shortly after training (Campeau and Davis, 1995), lesions were restricted to the Tel cortex. In the other study, lesioned rats showed enhanced fear generalization, thus preventing the precise analysis of memory retention (Jarrell et al., 1987). Other studies reporting the lack of effects of auditory cortical lesions on memory acquisition were performed before fear learning, thus allowing other brain structures to form and encode new memory traces.

Two recent studies have shown that acute reversible inactivation (Letzkus et al., 2011) and optogenetic manipulation (Weible et al., 2014) of the auditory cortex during training prevented auditory fear learning. However, both studies used complex tones, namely frequency-modulated sweeps (Letzkus et al., 2011) and temporally structured sounds (Weible et al., 2014), for CSs. Therefore, it remains unclear whether the observed amnesia was due to the acute blockade of the auditory cortex upon learning, preventing compensative neural mechanisms, or, alternatively, to the fact that complex auditory stimuli were used. In this framework, our study is the first to demonstrate that the auditory cortex is essential for consolidating fearful memories to simple CSs. It should be highlighted that, by blocking the auditory cortex in a temporary manner after training and by testing memory retention with a fully functional auditory cortex, we can be sure that amnesia, when present, is due to an impairment of memory processes and is not secondary to sensory perception and/or processing alteration or to an interruption of sensory information transmission to the amygdala. In addition, our data unraveled a new and important feature of the way the auditory cortex operates: during the early stages of memory consolidation, the different regions of the auditory cortex operate together, not independently, and they interact so as to influence each other's function.

\section{Differential recruitment of different regions of the auditory cortex}

In the formation of recent fearful memories, our data revealed marked differences between the participation of the Tel and the Te2. Unlike the Te1, the Te2 alone is necessary for late consolidation processes occurring $4 \mathrm{~d}$ after training, as well as for the early consolidation of remote memories (Grosso et al., 2015b). According to this view, neuronal activity was seen to increase more in $\mathrm{Te} 2$ than in the other higher-order cortex, Te3, or in the Te1 (Poremba et al., 1997, 1998; Bao et al., 2001, Holschneider et al., 2006). 
A

Recent fear memory

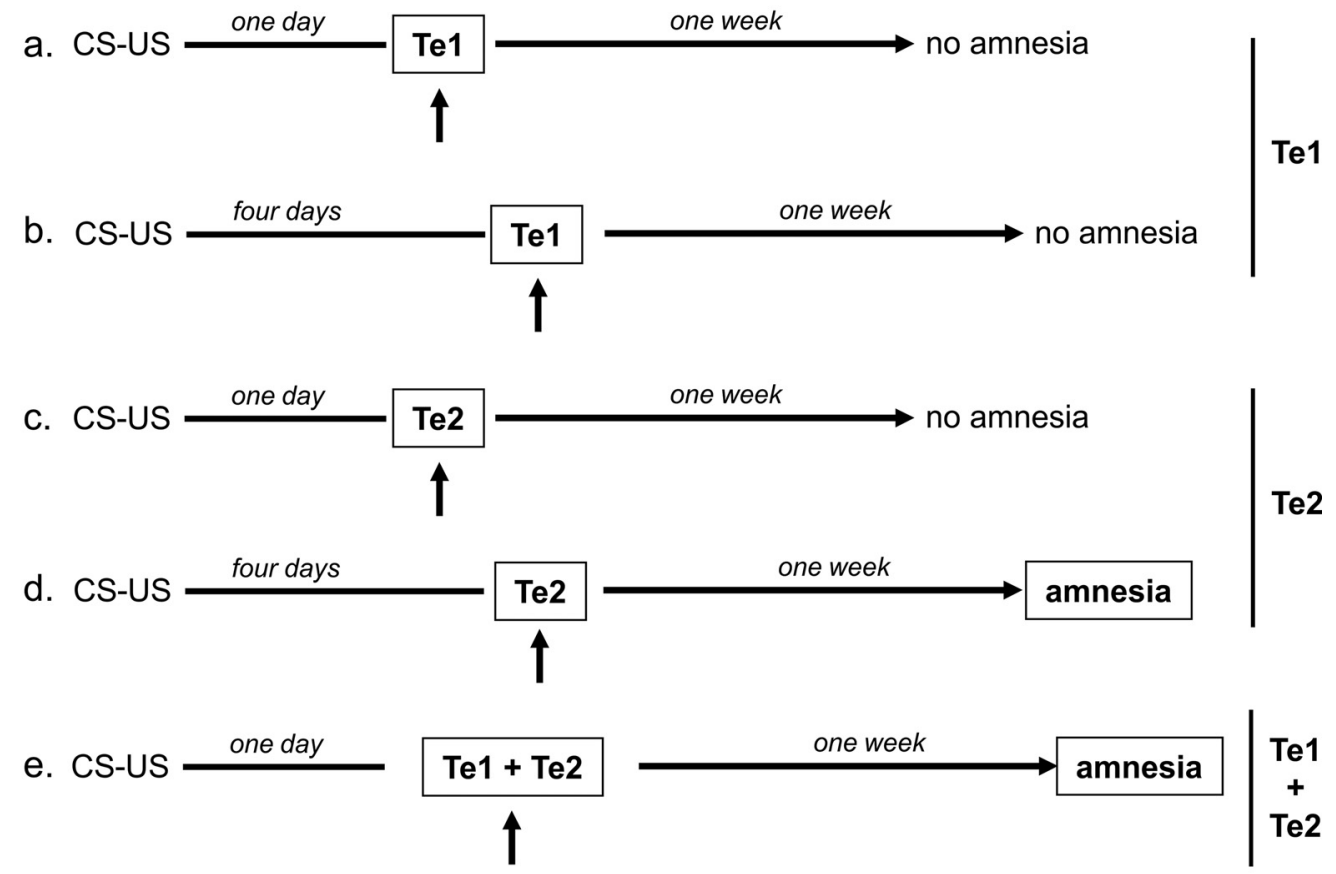

B

Remote fear memory

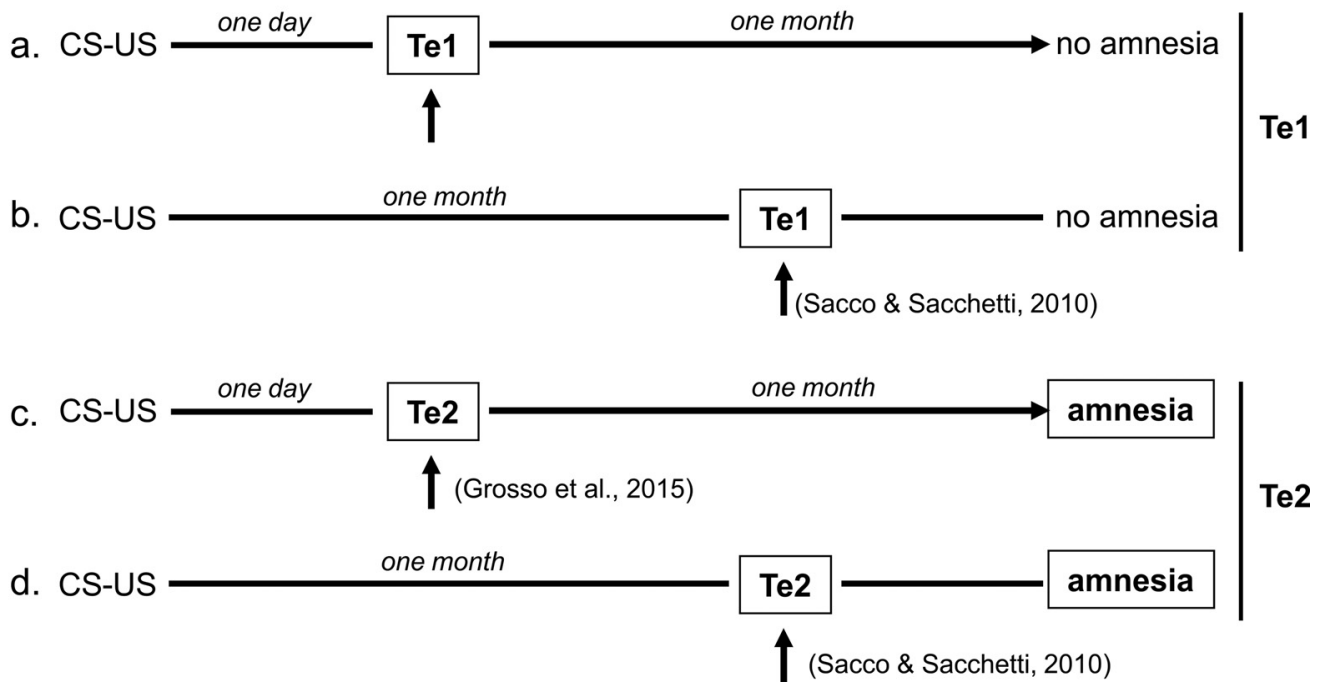

Figure 6. Schematic figure showing main effects of Te1 or Te2 blockade on recent and remote fearful memories to simple auditory CSs. To facilitate the comparison between Te1 and Te2 involvement in either recent $(\boldsymbol{A})$ or remote $(\boldsymbol{B})$ memory test, we reported the results obtained in the present (arrows) and our previous (arrows with citation) studies by temporary inactivating or irreversibly lesioning Te1 or Te2 cortices. Arrows indicate the blockade of the target site.

Te2 represents a key node for the assignment of the affective value to auditory stimuli (Grosso et al., 2015b; Cambiaghi et al., 2016). Neuronal activity in Te2 predicts the animals' ability to recognize auditory stimuli as aversive (Cambiaghi et al., 2016). Moreover, in Te2, there is a small fraction of neurons that respond exclusively to aversive or incentive stimuli and signal the valence rather than the salience of the stimuli (Grosso et al., 2015b). Pharmacogenetic silencing of memory-activated neurons causes amnesia and $\mathrm{Te} 2$ inactivation prevents changes in the valence of auditory cues (Grosso et al., 2015b). The latter study revealed that $\mathrm{Te} 2$ is necessary for appetitive memories too (see also Cambiaghi et al., 2015). More recently, we discovered that appetitive and aversive memories recruited different subregions in the Te2 (Grosso et al., 2016), thus suggesting that different neural circuits in the $\mathrm{Te} 2$ process positive and negative auditory stimuli. Intriguingly, $\mathrm{Te} 2$ is also connected with the nucleus accumbens (Romanski and Ledoux, 1993), a crucial site for appetitive processes.

Our data also showed that, in the absence of the Te2 cortex, $\mathrm{Te} 1$ is able to support discriminative fear memory retention. This 
observation is consistent with previous findings showing that learning-evoked plasticity in Tel is highly specific (Letzkus et al., 2011; Bieszczad and Weinberger, 2012; David et al., 2012; Pi et al., 2013; Yin et al., 2014). Nevertheless, in the present study, the Te1 cortex was never effective on its own, which is consistent with previous reports on recent (Campeau and Davis, 1995) and remote (Sacco and Sacchetti, 2010) fear memory retention. Therefore, the exact role of this cortical plasticity remains to be defined. Previous studies showed that the Te1 is dispensable for fear learning, whereas it is necessary for the extinction of these memories (Teich et al., 1989; Song et al., 2010). Interestingly, ApergisSchoute et al. (2014) reported differences in the activities of auditory cortices during fear extinction in humans, finding that the BOLD signal decreased progressively in a threat extinction paradigm in the amygdala and Te1, whereas the fear memory persisted throughout the extinction sessions in the higher-order auditory cortex (Apergis-Schoute et al., 2014). Therefore, we can hypothesize that, in the auditory cortex, there are multiple representations of auditory fear experience. Te2 may encode and store memories, whereas Te1 may be recruited for new phases of learning, such as during the early stages of memory consolidation processes and during the fear extinction procedure.

\section{Recent versus remote fearful memory retention circuits}

Our study was aimed at investigating the participation of the auditory cortex in consolidation processes occurring at the system level; that is, in the process that involves neural interactions between different brain areas. Our results revealed that, at the sensory neocortex level, the neural network that forms or stores auditory fear memories undergoes reorganization. In particular, our data suggest that, at early time intervals after learning, memory information is processed in a distributed network composed of both Te1 and Te 2 cortices. With the passage of time, memories become encoded in more circumscribed regions and therefore become susceptible to the block of only one site, as we observed when $\mathrm{Te} 2$ (but not $\mathrm{Te} 1$ ) was inactivated at $4 \mathrm{~d}$ after training.

We also found that Tel blockade did not interfere with the consolidation of remote fearful memories tested 1 month later, thus suggesting that memory-related processes occurring in $\mathrm{Te} 1$ are not necessary for the long-term storage of remote memories. These data differed from those of our previous study, in which we inactivated Te2 at $1 \mathrm{~d}$ after training and detected amnesic effects during the remote memory retention test (Grosso et al., 2015b). Together, these findings suggest that, although recent and remote memories are formed at the same time intervals upon encoding, they are in fact encoded through different pathways, with Te1 never being effective on its own for the formation of remote memories. Therefore, our data support the view that recent and remote fearful memories are mediated by parallel processes, so they are not constituted by a unique and sequential phenomenon.

\section{References}

Antunes R, Moita MA (2010) Discriminative auditory fear learning requires both tuned and nontuned auditory pathways to the amygdala. J Neurosci 30:9782-9787. CrossRef Medline

Apergis-Schoute AM, Schiller D, Ledoux JE, Phelps EA (2014) Extinction resistant changes in the human auditory association cortex following threat learning. Neurobiol Learn Mem 113:109-114. CrossRef Medline

Atiani S, David SV, Elgueda D, Locastro M, Radtke-Schuller S, Shamma SA, Fritz JB (2014) Emergent selectivity for task-relevant stimuli in higherorder auditory cortex. Neuron 82:486-499. CrossRef Medline

Bao S, Chan VT, Merzenich MM (2001) Cortical remodelling induced by activity of ventral tegmental dopamine neurons. Nature 412:79-83. CrossRef Medline
Bieszczad KM, Weinberger NM (2012) Extinction reveals that primary sensory cortex predicts reinforcement outcome. Eur J Neurosci 35:598-613. CrossRef Medline

Brosch M, Selezneva E, Scheich H (2011) Representation of reward feedback in primate auditory cortex. Front Syst Neurosci 5:5. CrossRef Medline

Cambiaghi M, Grosso A, Renna A, Concina G, Sacchetti B (2015) Acute administration of nicotine into the higher order auditory Te2 cortex specifically decreases the fear-related charge of remote emotional memories. Neuropharmacology 99:577-588. CrossRef Medline

Cambiaghi M, Grosso A, Likhtik E, Mazziotti R, Concina G, Renna A, Sacco T, Gordon JA, Sacchetti B (2016) Higher-order sensory cortex drives basolateral amygdala activity during the recall of remote, but not recently learned fearful memories. J Neurosci 36:1647-1659. CrossRef Medline

Campeau S, Davis M (1995) Involvement of subcortical and cortical afferents to the lateral nucleus of the amygdala in fear conditioning measured with fear-potentiated startle in rats trained concurrently with auditory and visual conditioned stimuli. J Neurosci 15:2312-2327. Medline

David SV, Fritz JB, Shamma SA (2012) Task reward structure shapes rapid receptive field plasticity in auditory cortex. Proc Natl Acad Sci U S A 109:2144-2149. CrossRef Medline

Frankland PW, Bontempi B (2005) The organization of recent and remote memories. Nat Rev Neurosci 6:119-130. Medline

Ghosh S, Chattarji S (2015) Neuronal encoding of the switch from specific to generalized fear. Nat Neurosci 18:112-120. CrossRef Medline

Grosso A, Cambiaghi M, Concina G, Sacco T, Sacchetti B (2015a) Auditory cortex involvement in emotional learning and memory. Neuroscience 299:45-55. CrossRef Medline

Grosso A, Cambiaghi M, Renna A, Milano L, Roberto Merlo G, Sacco T, Sacchetti B (2015b) The higher order auditory cortex is involved in the assignment of affective value to sensory stimuli. Nat Commun 6:8886. CrossRef Medline

Grosso A, Cambiaghi M, Milano L, Renna A, Sacco T, Sacchetti B (2016) Region- and layer-specific activation of the higher order auditory cortex $\mathrm{Te} 2$ after remote retrieval of fear or appetitive memories. Cereb Cortex. In press.

Holschneider DP, Yang J, Sadler TR, Nguyen PT, Givrad TK, Maarek JM (2006) Mapping cerebral blood flow changes during auditory-cued conditioned fear in the nontethered, nonrestrained rat. Neuroimage 29: 1344-1358. CrossRef Medline

Jaramillo S, Zador AM (2011) The auditory cortex mediates the perceptual effects of acoustic temporal expectation. Nat Neurosci 14:246-251. CrossRef Medline

Jarrell TW, Gentile CG, Romanski LM, McCabe PM, Schneiderman N (1987) Involvement of cortical and thalamic auditory regions in retention of differential bradycardiac conditioning to acoustic conditioned stimuli in rabbits. Brain Res 412:285-294. CrossRef Medline

Kolb B, Tees RC (1990) The cerebral cortex of the rat. Cambridge, MA: MIT.

Laxmi TR, Stork O, Pape HC (2003) Generalisation of conditioned fear and its behavioural expression in mice. Behav Brain Res 145:89-98. CrossRef Medline

Ledoux JE (2000) Emotion circuits in the brain. Annu Rev Neurosci 23: 155-184. CrossRef Medline

Ledoux JE, Romanski L, Xagoraris A (1989) Indelibility of subcortical emotional memories. J Cogn Neurosci 1:238-243. CrossRef Medline

Lesburguères E, Bontempi B (2011) Making our memories last: the necessity of an early neocortical tagging process [article in French]. Med Sci (Paris) 27:1048-1050. CrossRef Medline

Lesburguères E, Gobbo OL, Alaux-Cantin S, Hambucken A, Trifilieff P, Bontempi B (2011) Early tagging of cortical networks is required for the formation of enduring associative memory. Science 331:924-928. CrossRef Medline

Letzkus JJ, Wolff SB, Meyer EM, Tovote P, Courtin J, Herry C, Lüthi A (2011) A disinhibitory microcircuit for associative fear learning in the auditory cortex. Nature 480:331-335. CrossRef Medline

Martin JH, Ghez C (1999) Pharmacological inactivation in the analysis of the central control of movement. J Neurosci Methods 86:145-159. CrossRef Medline

McGaugh JL (2000) Memory: a century of consolidation. Science 287: 248-251. CrossRef Medline

McGaugh JL (2015) Consolidating memories. Annu Rev Psychol 66:1-24. CrossRef Medline 
Otchy TM, Wolff SB, Rhee JY, Pehlevan C, Kawai R, Kempf A, Gobes SM, Ölveczky BP (2015) Acute off-target effects of neural circuit manipulations. Nature 528:358-363. CrossRef Medline

Paxinos G (2004) The rat nervous system. San Diego: Academic.

Paxinos G, Watson C (1986) The rat brain in stereotaxic coordinates. New York: Academic.

Pi HJ, Hangya B, Kvitsiani D, Sanders JI, Huang ZJ, Kepecs A (2013) Cortical interneurons that specialize in disinhibitory control. Nature 503: 521-524. CrossRef Medline

Poremba A, Jones D, Gonzalez-Lima F (1997) Metabolic effects of blocking tone conditioning on the rat auditory system. Neurobiol Learn Mem 68:154-171. CrossRef Medline

Poremba A, Jones D, Gonzalez-Lima F (1998) Classical conditioning modifies cytochrome oxidase activity in the auditory system. Eur J Neurosci 10:3035-3043. CrossRef Medline

Riedel G, Micheau J, Lam AG, Roloff EL, Martin SJ, Bridge H, de Hoz L, Poeschel B, McCulloch J, Morris RG (1999) Reversible neural inactivation reveals hippocampal participation in several memory processes. Nat Neurosci 2:898-905. CrossRef Medline

Romanski LM, Ledoux JE (1992a) Bilateral destruction of neocortical and perirhinal projection targets of the acoustic thalamus does not disrupt auditory fear conditioning. Neurosci Lett 142:228-232. CrossRef Medline

Romanski LM, Ledoux JE (1992b) Equipotentiality of thalamoamygdala and thalamo-cortico-amygdala circuits in auditory fear conditioning. J Neurosci 12:4501-4509. Medline

Romanski LM, Ledoux JE (1993) Information cascade from primary auditory cortex to the amygdala: corticocortical and corticoamygdaloid projections of temporal cortex in the rat. Cereb Cortex 3:515-532. CrossRef Medline

Sacchetti B, Lorenzini CA, Baldi E, Tassoni G, Bucherelli C (1999) Auditory thalamus, dorsal hippocampus, basolateral amygdala, and perirhinal cortex role in the consolidation of conditioned freezing to context and to acoustic conditioned stimulus in the rat. J Neurosci 19:9570-9578. Medline

Sacchetti B, Baldi E, Lorenzini CA, Bucherelli C (2002) Cerebellar role in fear-conditioning consolidation. Proc Natl Acad Sci U S A 99:84068411. CrossRef Medline

Sacco T, Sacchetti B (2010) Role of secondary sensory cortices in emotional memory storage and retrieval in rats. Science 329:649-656. CrossRef Medline

Song EY, Boatman JA, Jung MW, Kim JJ (2010) Auditory cortex is important in the extinction of two different tone-based conditioned fear memories in rats. Front Behav Neurosci 4:24. CrossRef Medline

Teich AH, McCabe PM, Gentile CC, Schneiderman LS, Winters RW, Liskowsky DR, Schneiderman N (1989) Auditory cortex lesions prevent the extinction of Pavlovian differential heart rate conditioning to tonal stimuli in rabbits. Brain Res 480:210-218. CrossRef Medline

van Duuren E, van der Plasse G, van der Blom R, Joosten RN, Mulder AB, Pennartz CM, Feenstra MG (2007) Pharmacological manipulation of neuronal ensemble activity by reverse microdialysis in freely moving rats: a comparative study of the effects of tetrodotoxin, lidocaine, and muscimol. J Pharmacol Exp Ther 323:61-69. CrossRef Medline

Vervliet B, Kindt M, Vansteenwegen D, Hermans D (2010) Fear generalization in humans: Impact of prior non-fearful experiences. Behav Res Ther 48:1078-1084. CrossRef Medline

Villa AE, Tetko IV, Hyland B, Najem A (1999) Spatiotemporal activity patterns of rat cortical neurons predict responses in a conditioned task. Proc Natl Acad Sci U S A 96:1106-1111. CrossRef Medline

Weible AP, Liu C, Niell CM, Wehr M (2014) Auditory cortex is required for fear potentiation of gap detection. J Neurosci 34:15437-15445. CrossRef Medline

Weinberger NM (2007) Auditory associative memory and representational plasticity in the primary auditory cortex. Hear Res 229:54-68. CrossRef Medline

Weinberger NM (2011) The medial geniculate, not the amygdala, as the root of auditory fear conditioning. Hear Res 274:61-74. CrossRef Medline

Weinberger NM (2015) New perspectives on the auditory cortex: learning and memory. Handb Clin Neurol 129:117-147. CrossRef Medline

Yin P, Fritz JB, Shamma SA (2014) Rapid spectrotemporal plasticity in primary auditory cortex during behavior. J Neurosci 34:4396-4408. CrossRef Medline

Zhuravin IA, Bures J (1991) Extent of the tetrodotoxin induced blockade examined by pupillary paralysis elicited by intracerebral injection of the drug. Exp Brain Res 83:687-690. Medline

Zilles K (1985) The cortex of the rat. New York: Springer.

Znamenskiy P, Zador AM (2013) Corticostriatal neurons in auditory cortex drive decisions during auditory discrimination. Nature 497:482-485. CrossRef Medline 